\title{
Antibacterial Activity of Methanolic Extracts from Lyngbya truncicola and Pseudanabaena sp.
}

\author{
Olvera-Ramírez Roxana ${ }^{1}$, Pineda-López Margarita ${ }^{2}$ and \\ Y Medina-Jaritz Nora Beatriz ${ }^{1 *}$
}

\begin{abstract}
${ }^{1}$ Department of Botany. National School of Biological Sciences. National Polytechnic Institute prol. De Carpio s / n, Casco de Santo Tomas. Mexico City. C.P. 11430. Mexico

${ }^{2}$ Department of Microbiology. National School of Biological Sciences. National Polytechnic Institute. prol. De Carpio s / n, Casco de Santo Tomas. Mexico City. C.P. 11430. Mexico
\end{abstract}

*Corresponding author

\section{A B S T R A C T}

\section{Keywords}

Antibacterial activity, cyanobacteria, Kirby-Bauer, Lyngbya truncicola, methanolic extracts, Pseudanabaena sp.

\section{Article Info}

Received: 08 October 2021 Accepted: 30 October 2021 Available Online: 10 November 2021
One of the consequences of the abuse in the use of antibiotics is the emergence of resistant bacteria, wich causes new drugs to be sought, and thus makes it necessary to seek alternatives sources. There are many natural compounds, obtained from cyanobacteria, that have an inhibitory effect against various pathogenic bacteria. In this group of cyanobacteria are those belonging to the Lyngbya and Pseudanabaena genera; therefore, the aim of this work was to evaluate the antibacterial activity of methanolic extracts from $L$. truncicola and Pseudanabaena sp. against reference strains: Staphylococcus aureus, Pseudomonas aeruginosa, Bacillus subtilis, Escherichia coli and Salmonella enterica ssp. enterica serovar Typhimurium. The cyanobacteria were propagated in BG-11 medium with constant aeration and a 12 hour light: dark photoperiod. The antibacterial activity test was carried out by the Kirby-Bauer method. The antibacterial effect was observed as growth inhibition halos. All the microorganisms presented suffered inhibition, the greater effect was produced on $S$. enterica ssp. enterica serovar Typhimurium. The largest halos were obtained with the extract of Lyngbya truncicola.

\section{Introduction}

Despite their success in medicine, the number of new antibiotics approved for use is on the decline. In the US alone, the number of new FDA approved antibiotics has been declining since the $1980 \mathrm{~s}$ for seemingly financial reasons. The entire process for the development of an antibiotic costs between \$ 600 to $\$ 1$ million dollars. Putting the resistance development factor aside; these are not used for a prolonged time and their use is 
regulated to use them only when necessary, unlike the medications for chronic diseases that accompany the patient for the rest of their life and must constantly acquire them.

The investment does not seem profitable (Spellberg, 2008); however, the increase in bacteria resistant to antimicrobials represents losses at an economic level due to the increase in morbidity, mortality, hospital stays, days lost, investment in treatments, and time that patients remain infected, which affects the possibility of contagion and spread of the pathogen and at the current rate, a really significant economic loss is expected for the year 2050 (WHO, 2015; WHO, 2017; Gervas, 2000; Gilbert, 2010; O'Neill, 2014) and a great threat to public health to world level, which is why the need to develop new antibiotics arises, and therefore alternative sources that are not toxic to humans are now being sought such as natural antimicrobials, which undoubtedly have an important role in protecting against infections. This new direction in research has been the subject of many studies of the antimicrobial effect of various organisms including cyanobacteria (Gershwin and Belay, 2008).

Research in the last decades has identified cyanobacteria metabolites with cytotoxic, antifungal, antibacterial and antiviral activity. Most of the isolated substances belong to the groups of polyketides, amides, alkaloids and peptides (Borowitzka, 1995).

Cyanobacteria have been shown to produce compounds with potential applications in biomedicine and environmental health.

These have been identified as one of the most promising groups of organisms from which new biochemically active natural products are isolated, substances other than cyanotoxins and which demonstrate a wide spectrum of biological activities such as antibacterial, antiviral, fungicidal, enzyme inhibitors, immunosuppressants., cytotoxic and substances with algicidal activities; that have been isolated from cyanobacterial biomass or cell-free culture medium (Gershwin and Belay, 2008; Olaizola, 2003).

In many studies the antibacterial activity of some cyanobacteria and their extracts has been tested. Mian et al., (2003) found that 44 lipophilic and hydrophilic extracts obtained from 22 samples of cyanobacteria isolated from fresh and terrestrial water, showed biological activity; $54.5 \%$ of all extracts showed activity against Gram positive bacteria, while $9.1 \%$ had antifungal activity against $C$. albicans. No extract had activity against Gram negative bacteria.

The secondary metabolites of cyanobacteria are associated with toxic, hormonal, antineoplastic and antimicrobial effects (Huang and Zimba, 2019; Singh et al., 2005). The chemical structures of these secondary metabolites are not fully known, the antimicrobial effects of aqueous extracts and organic solvents of cyanobacteria are visualized in bioassays using selected microorganisms as test organisms (SilvaStenico et al., 2013).

Commonly applied methods are based on the principle of agar diffusion. Antimicrobial effects are demonstrated as visible zones of growth inhibition. Bacterial biological tests cover various bacteria such as: Micrococcus luteus, Bacillus subtilis, B. cereus and Escherichia coli, which are frequently used to detect antibiotic residues in food (Jaiswal et al., 2011).

Therefore, the objective of this work was to determine if the methanolic extracts of Lyngbya truncicola and Pseudanabaena ssp. have an inhibitory effect on the growth of reference bacterial strains. 


\section{Materials and Methods}

\section{Cyanobacteria and bacterial strains}

The cyanobacterial strains Lyngbya truncicola and Pseudanabaena ssp., used in this work, are found in the ceparium of the Plant Physiology laboratory of the National School of Biological Sciences. These strains were cultivated, and the biomass obtained was used as material for the preparation of the extract. They were cultivated in BG-11 medium, at $28^{\circ} \mathrm{C}$, with light and continuous aeration.

The antibacterial activity of each extract was evaluated using five reference strains, two Gram positive strains (Bacillus subtilis ATCC6633 and Staphylococcus aureus ATCC25923) and three Gram negative strains (Escherichia coli ATCC8739, Pseudomonas aeruginosa ATCC9028 and Salmonella enterica ssp. enterica serovar Typhimurium ATCC6534.

\section{Preparation of the extracts}

From $40 \mathrm{~mL}$ of cultivation of each cyanobacteria with 4 months of growth, each cultivation was filtered through a Whatman No. 1 filter paper. The retained biomass on the filter paper was scraped from the surface with a spatula, and was collected in glasses of precipitate and weighed; For each gram of biomass collected, $60 \mathrm{~mL}$ of ethanol and $2 \mathrm{~mL}$ of acetic acid were added, and finally were left to rest for $24 \mathrm{~h}$. After the methanol and acetic acid were evaporated to dryness by heating on a rotary evaporator, the resulting concentrate was resuspended in methanol until a concentration of $1 \mathrm{~g} / \mathrm{mL}$ was obtained.

Evaluation of the antibacterial activity of the extracts

The bacterial strains were adjusted with an isotonic saline solution to tube 1 of the Mac
Farland nephelometer. After adjusting, a 1:10 dilution of that tube was made to obtain a concentration of $3 \times 10^{7} \mathrm{UFC} / \mathrm{mL}$, they were inoculated on Müller-Hinton agar plates. Afterwards 5 sterile filter paper discs of 0.68 $\mathrm{cm}$ diameter impregnated with $30 \mu \mathrm{L}$ of the test extracts and another with $30 \mu \mathrm{L}$ of methanol were placed, five plates were made for each strain and were incubated for $24 \mathrm{~h}$ at $37^{\circ} \mathrm{C}$. The inhibition halos formed around the discs were measured (Hudzicky, 2009). A one-way ANOVA Dunnett statistical analysis was applied, using the GraphPad Prism 6.0 program (GraphPad Software, Inc., La Jolla, CA, USA).

\section{Results and Discussion}

The methanolic extract of Lyngbya truncicola showed antimicrobial activity (Figure 1) against all the strains used. However, for $E$. coli and $P$. aeruginosa a heteroresistance phenomenon was observed (Fig. 2) which may be the result of an epigenetic phenomenon by which isogenic subpopulations are isolated with less sensitivity when the bacterial population is subjected to concentrations above of the value of the minimum inhibitory concentration or it may very well can manifest itself due to the cause-effect relationship between the level of exposure to a substance and the magnitude of the response to it, the toxicity being directly proportional to the dose in most cases (Peña et al., 2004). The methanolic extract of Pseudanabaena ssp. showed antimicrobial activity against all strains used (Fig. 3). The observed halos were compared by means of a statistical analysis (Figures 4 and 5), the significant results are indicated with asterisks. It is possible that these results are due to the content of linoleic acid and other fatty acids whose antimicrobial activity has already been proven (Benkendorff et al., 2005), or to the synergistic effect between these fatty acids (Desbois and Smith, 2010). 
Fig.1 Inhibition effect of the Lyngbya sp. on the reference strains. a) Bacillus subtilis ATCC 6633, b) Salmonella typhi ATCC 6534, c) Staphylococcus aureus ATCC 25923.

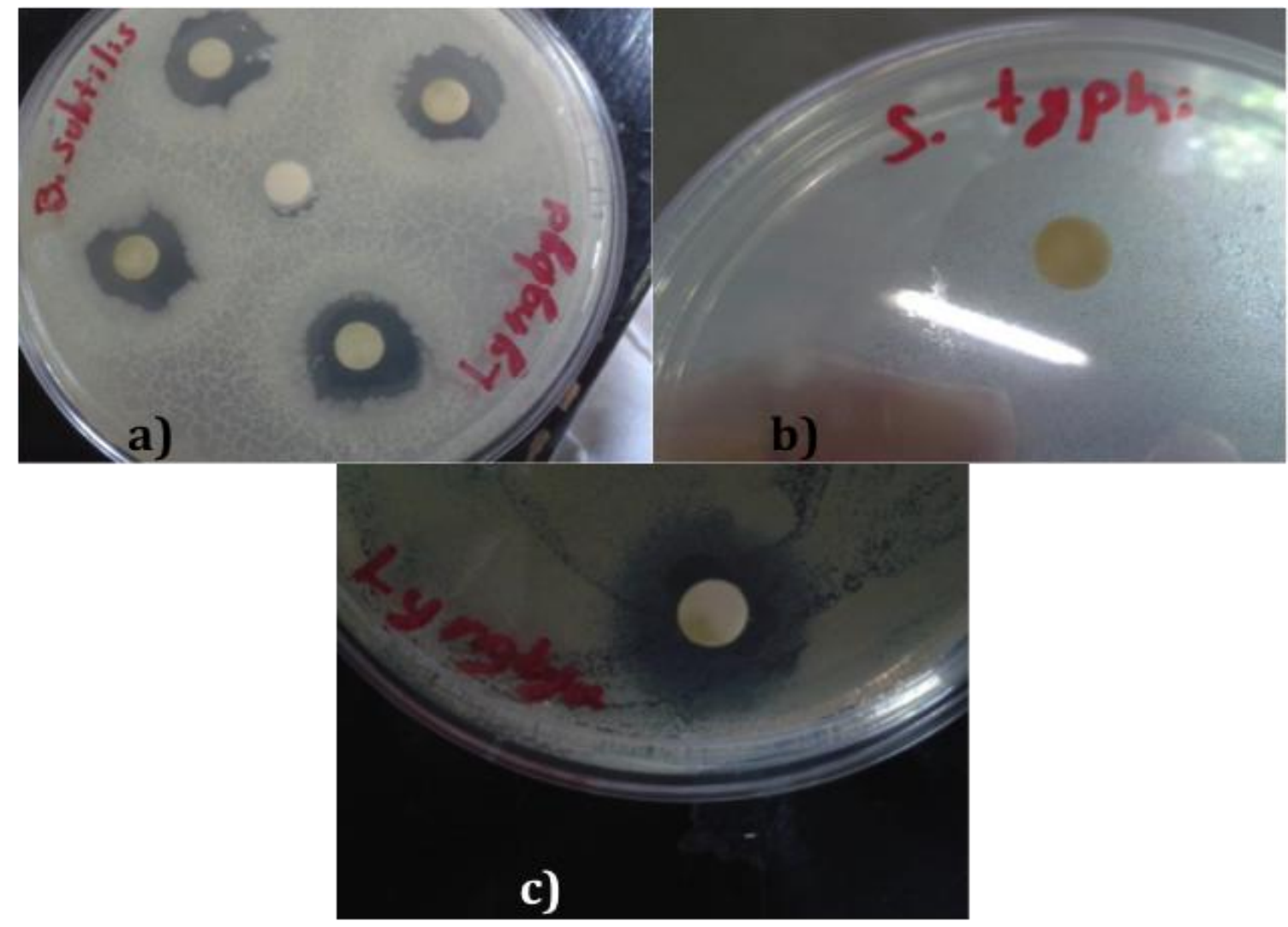

Fig.2 Inhibition and heteroresistance effect of the Lyngbya truncicola on the reference strains. a) Escherichia coli ATCC 8739, b) Pseudomonas aeruginosa ATCC 9027.

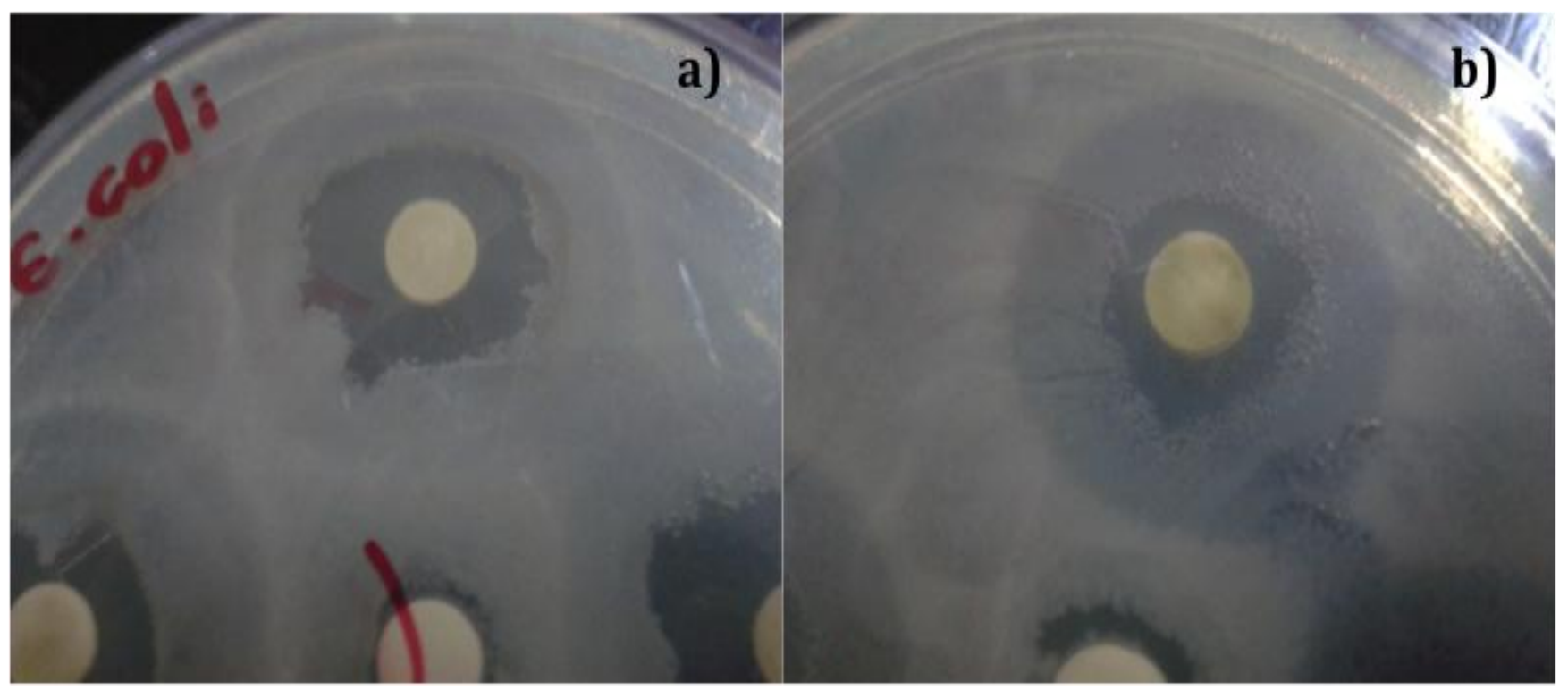


Fig.3 Inhibition effect of the extract of Pseudanabaena sp. on the reference strains. a) Staphylococcus aureus ATCC 25923, b) Pseudomonas aeruginosa ATCC 9027, c) Escherichia coli ATCC 8739, d) Bacillus subtilis ATCC 6633, e) Salmonella typhi ATCC 6534.

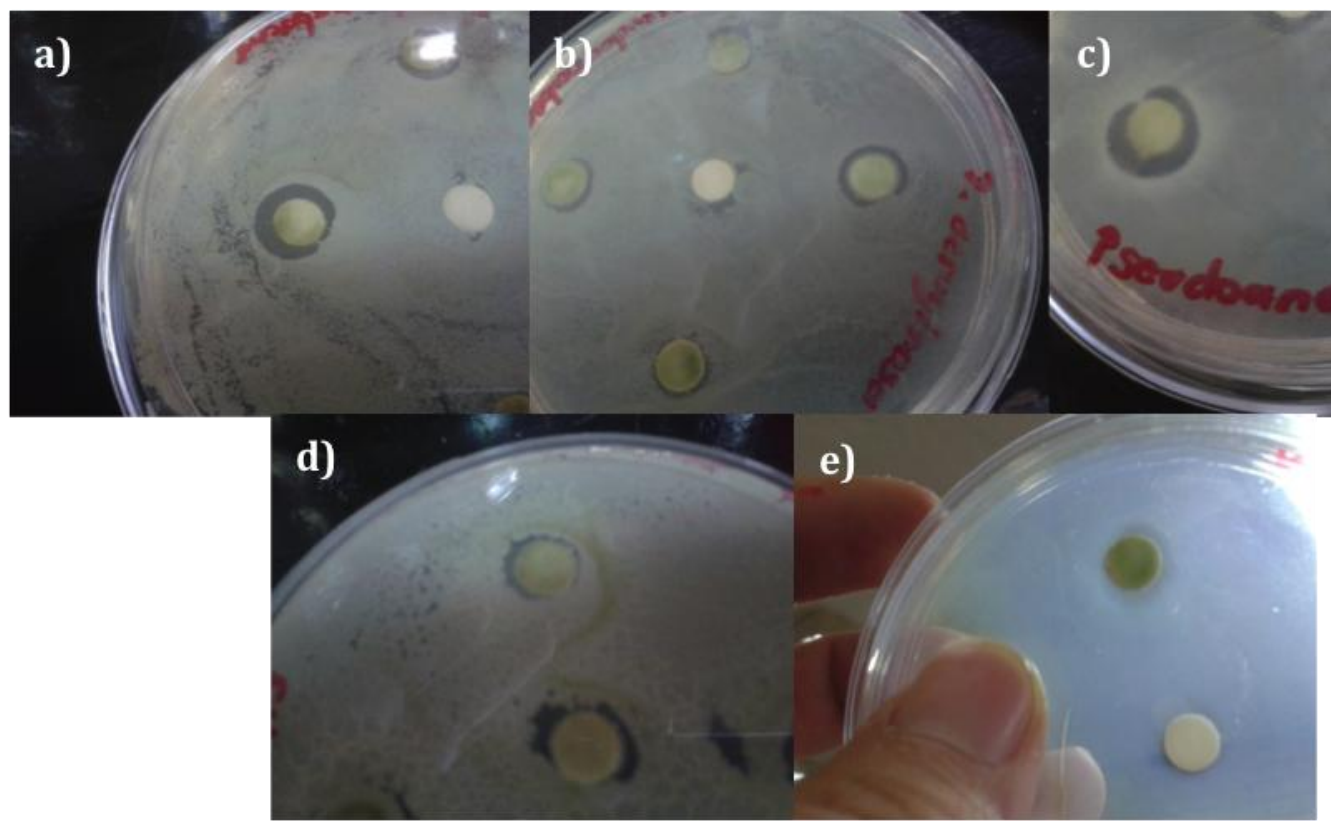

Fig.4 Comparative graph of the growth inhibition halos of the reference strains due to the effect of the methanolic extract of Pseudanabaena sp.

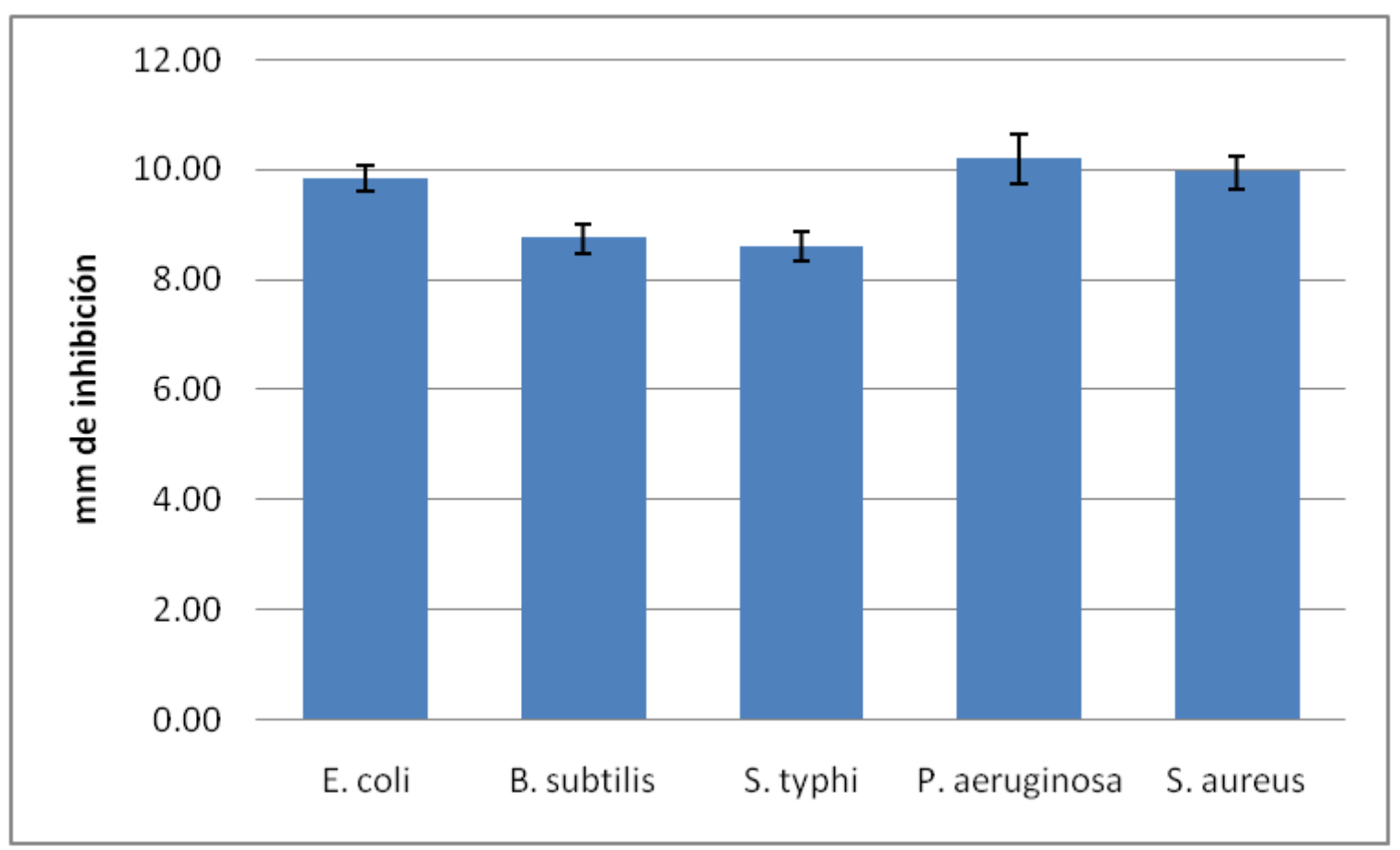


Fig.5 Comparative graph of the growth inhibition halos of the reference strains due to the effect of the methanolic extract of Lyngbya truncicola.

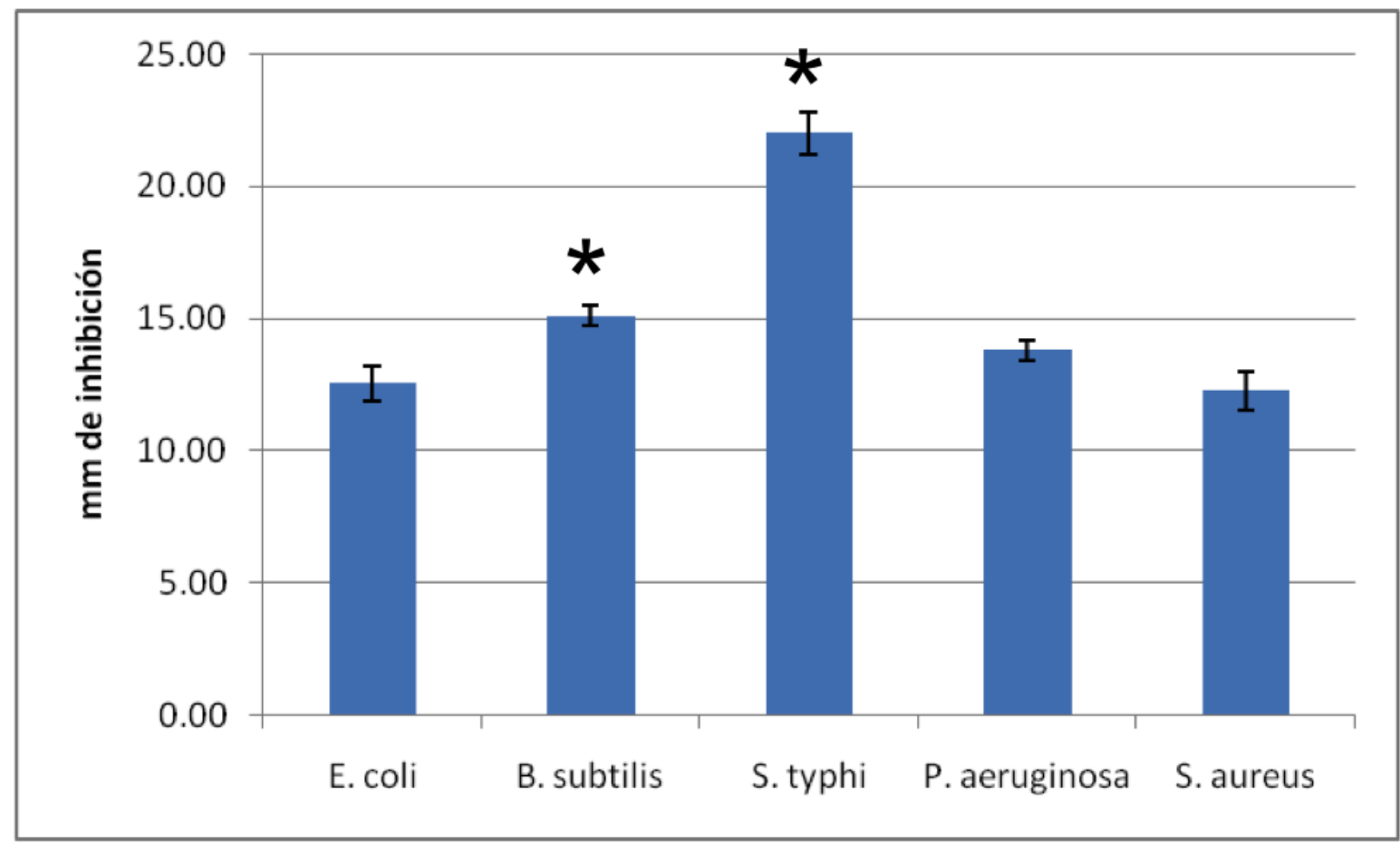

However, these cyanobacteria excrete variable amounts of other products of their metabolism such as vitamins, proteins, carbohydrates, etc. (Ozdemir et al., 2004), which may be responsible for this bactericidal activity. Several studies carried out with water-soluble and fat-soluble extracts of cyanobacteria have proven the antibacterial effectiveness of these compounds on both Gram negative and Gram positive bacteria (Jaki et al., 1999); In other studies, from 22 strains of filamentous cyanobacteria, $54.5 \%$ of the polar extracts obtained produced sensitivity on Gram positive bacteria; but no on Gram negative bacteria (Mian et al., 2003). The two filamentous cyanobacteria tested in this study produced secondary metabolites that have a polar chemical characteristic because they were extracted with a 1:30 acetic acidmethanol solution, the capacity of the solvent used in the extraction has to be taken heavily in consideration, because the extracts obtained with methanolic solvents have a greater antimicrobial activity, since they are believed to have a high toxicity (El Sheek et al., 2006), such as coriolic acid that was detected in methanolic extracts from some cyanobacteria (Mundt et al., 2003). The selection of the solvent mixture used was based on the procedure described in other studies, where antibacterial activity of secondary metabolites with polar nature was found (Newbold et al., 1999). On the other hand, another study reported antimicrobial activity in the biomass extracts of Lyngbya ssp. as those obtained in the present work, although a higher activity was observed in lyophilized biomass extracted with methanol (Torres Ariño, 2002).

Considering all previously mentioned, we can reach the conclusion that the results are satisfactory and that this work can be the basis for subsequent studies that seek to purify and characterize the metabolite responsible for the activity shown, to propose the tools to face bacterial resistance to antibiotics. (Gerusa et 
al., 2015), for the treatment of opportunistic infections and even for infections caused by pathogenic bacteria such as Salmonella enterica ssp. enterica serovar Typhimurium, since in recent years, the production of new antibiotics has decreased considerably and resistance to them has emerged as a problem with unpredictable consequences (FernándezRiverón et al., 2003; Monreal-García et al., 2013; WHO, 2017).

\section{References}

Benkendorff, K., Davis, A. R., Rogers, C. N., Bremner, J. W. 2005. Free fatty acids and sterols in the benthic spawn of aquatic molluscs, and their associated antimicrobial properties. J. Exp. Mar. Biol. Ecol., 316 (1), 29-44.

Borowitzka, M. A., 1995. Microalgae as sources of pharmaceuticals and other biologically active compounds. J. App. Phyc., 7(1), 3-15.

Desbois, A. P., Smith, V. J. 2010. Antibacterial free fatty acids: activities, mechanisms of action and biotechnological potential. Appl. Microbiol. Biotechnol. 85, 1629-1642.

EI-Sheekh, M. M., Osman, M. E. H., Dyab, M. A., Amer, M. S. 2006. Production and characterization of antimicrobial active substance from cyanobacterium. Nostoc muscorum. Env. Toxicol. 21, 42-50.

Fernández-Riverón, F., López-Hernández, J., Ponce-Martínez, L. M., MachadoBetarte, C. 2003. Resistencia Bacteriana. Rev. Cub. Med. Milit. 32, 44-48.

Gershwin, M. E., Belay A. 2008. Spirulina in human nutrition and health. CRC Pres.

Gerusa, N. A. S., Ross, G. M., Scott, J. A. 2015. Cyanobacteria and eukaryotic microalgae as potential sources of antibiotics. Phycol., 54 (3), 271-282.

Gervas, J. 2000. La resistencia a los antibióticos, un problema de salud pública. Atenc. Prim., 25 (8), 589-596.

Gilbert, D. N., Guidos, R. J., Boucher, H. W., Talbot, G. H., Spellberg, B., Edwards Jr, J. E. 2010. The 10x'20 Initiative: Pursiung a Global Commitment to Develop 10 New Antibacterial Drugs by 2020. Clin. Infect. Dis. 50: 10811083.

Huang, S., Zimba, P. V. 2019. Cyanobacterial bioactive metabolites - A review of their chemistry and biology. Harmful Alg. 83, 42-94.

Hudzicky, J. (2009). Kirby-Bauer Disk Diffusion Susceptibility Test Protocol. ASM Conference for Under graduate Educators.

Jaiswal, P., Prasanna, R., Singh, P. K. 2011. Characterization of the Biocidal Spectrum of Extracellular Filtrates of Microcystis aeruginosa. Indian $\mathrm{J}$ Microbiol. 51(4), 509-14.

Jaki, B. Orjala, J., Bürgi, H.-R., Sticher, O. 1999. Biological Screening of Cyanobacteria for Antimicrobial and Molluscicidal Activity, Brine Shrimp Lethality, and Cytotoxicity. Pharmac. Biol., 37 (2), 138-143.

Mian, P., Heilmann, J. Bürgi, H.-R., Sticher, O. 2003. Biological Screening of Terrestrial and Freshwater Cyanobacteria for Antimicrobial Activity, Brine Shrimp Lethality, and Cytotoxicity, Pharmac. Biol., 41 (4), 243-247.

Monreal-García, H. M., Delgado-Alvarado, E. A., Medina-Medrano, J. R., TorresRicario, R., Reyes-Martínez, A., Cobaleda-Velasco, M., Chaidez-Ayala, A. 2013. Antibióticos y la resistencia bacteriana actual: una revisión bibliográfica. Vidsupra, 5 (2), 100-105.

Mundt, S., Kreitlowy, S., Jansen, R. 2003. Fatty acids with antibacterial activity from the cyanobacterium Oscillatoria redekei HUB 051. J. App. Phyc. 15, 
263- 267.

Newbold, R. W., Jensen, P. R., Fenical, W., Pawlik, J. R. 1999. Antimicrobial activity of Caribbean sponge extracts. Aquat. Micr. Ecol., 19, 279-284.

Olaizola, M. 2003. Commercial development of microalgal biotechnology: from the test tube to the marketplace. Biomol. Eng. 20, 459-466.

O'Neill, J. (2014). Review on Antimicrobial Resistance. Antimicrobial Resistance: Tackling a Crisis for the Health and Wealth of Nations. UK Gov. Wellcome Trust.

Ozdemir, G., Karabay, N. U., Dalay, M. C., Pazarbasi, B. 2004. Antibacterial activity of volatile component and various extracts of Spirulina platensis. Phytoth. Res.18, 754-757.

Peña, C., Fernández-Sabé, N., Domínguez, M. A., Pujol, M., Martínez-Castelao, A., Ajats, J., Gudiol, F., Ariza, J. (2004). Staphylococcus aureus nasal carriage in patients on haemodialysis: role of cutaneus colonization. J. Hosp. Infect. 58, 20-27.

Silva-Stenico, M. E., Kaneno, R., Zambuzi, F. A., Vaz, M. G., Alvarenga, D. O., Fiore, M. F. 2013. Natural products from cyanobacteria with antimicrobial and antitumor activity. Curr. Pharm. Biotechnol. 14(9), 820-8.

Singh, S., Bhushan, N. K., Banerjee, U. C. 2005. Bioactive Compounds from Cyanobacteria and Microalgae: An Overview, Crit. Rev. Biot. 25(3), 7395.

Spellberg, B., Guidos, R., Gilbert, D., Bradley, J., Boucher, H. W., Scheld, W. M., Bartlett, J. G., Edwards Jr., J. E., The Infectious Diseases Society of America. 2008. The Epidemic of Antibiotic-Resistant Infections: A Call to Action for the Medical Community from the Infectious Diseases Society of America. Clin. Infect. Dis., 46 (2), 155-164.

Torres-Ariño, A. 2002. Uso de cianobacterias en la producción de antibióticos Cienc. y Mar., 8 (23), 43-52.

World Health Organization (2015). Global action plan on antimicrobial resistance. World Health Organization.

WHO (2017). Global priority list of antibioticresistant bacteria to guide research, discovery, and development of new antibiotics. World Health Organization.

\section{How to cite this article:}

Olvera-Ramírez Roxana, Pineda-López Margarita and Medina-Jaritz Nora Beatriz, Y. 2021. Antibacterial Activity of Methanolic Extracts from Lyngbya truncicola and Pseudanabaena sp. Int.J.Curr.Microbiol.App.Sci. 10(11): 192-199. doi: https://doi.org/10.20546/ijcmas.2021.1011.022 